\title{
LA APLICACIÓN DEL ARCO DE HERRADURA EN EL PANTEÓN (ROMA) Y SU PROYECCIÓN SIMBÓLICA EN LA ESTELA DE VALENS (LEÓN, NW HISPANIA)
}

\author{
Enrique Jorge Montenegro Rúa \\ montenegro_rua@yahoo.es \\ INDEPENDENT RESEARCHER, PHD.
}

\section{Abstract}

Horseshoe arches samples in funerary steles from north-western Hispania are usually identified as simple geometric decorative motifs. This opinion has also been associated with what is represented in the stele of Valens (León, NW Spain), despite the fact that the artistic quality of the bas-relief allows to link it better with an architectural element.

Likewise, it is very remarkable the practical absence of references in specialized historiography to another significant sample of horseshoe arch, despite being part of one of the most important classical monuments: the Pantheon of Rome.

Located on the inside face of the door, the prominence of this majestic arch in the construction design of the Pantheon explains the symbolic meaning of what is represented in the stele of Valens.

\section{INTRODUCCIÓN}

Este acercamiento al estudio del arco de herradura en época romana fue suscitado por su presencia sobre el vano de acceso a Santa Eulalia de Bóveda (Lugo) ${ }^{1}$, a pesar de no definirse en todo su esplendor porque sólo se prolonga por debajo del diámetro horizontal en $1 / 4 \mathrm{del}^{\mathrm{radio}}{ }^{2}$ (Fig. 1). De manera todavía más incipiente, también estaría justificada su existencia en el arco que corona el ábside rectangular ubicado en la cabecera del monumento ${ }^{3}$.

Teniendo en cuenta que el elemento arquitectónico lucense está considerado como una de las muestras constructivas más antigua de Occidente romano surge la necesidad de comprobar cómo se manifiesta este tipo de arco en otras expresiones artísticas de la misma época y sus posibles precedentes.

Para este tipo de estudio, resulta insólita la escasa repercusión historiográfica del arco de herradura ubicado en el Panteón de Roma.

1 Recientemente he defendido una tesis doctoral sobre este monumento romano en la Universidad Autónoma de Madrid dirigida por Carmen Fernández Ochoa, catedrática de Arqueología de dicha universidad (MonTENEGro RúA, 2016), donde el análisis de sus características arquitectónicas y el discurso iconográfico asociado al repertorio decorativo permiten identificar un sepulcro monumental romano como última morada de iniciados dionisíacos.

2 Camps Cazorla, 1953, p. 61-62.

3 Castillo, 1927, p. 140. Para Gómez-Moreno (1949, p. 420) ambos arcos sobrepasarían en un 1/4 de radio el semicírculo. Igual equiparación aduce LóPEZ-MARTí (1934, p. 17-18) pero se limita a indicar que no alcanzan la medida prototípica visigoda de $1 / 3$ de radio. 


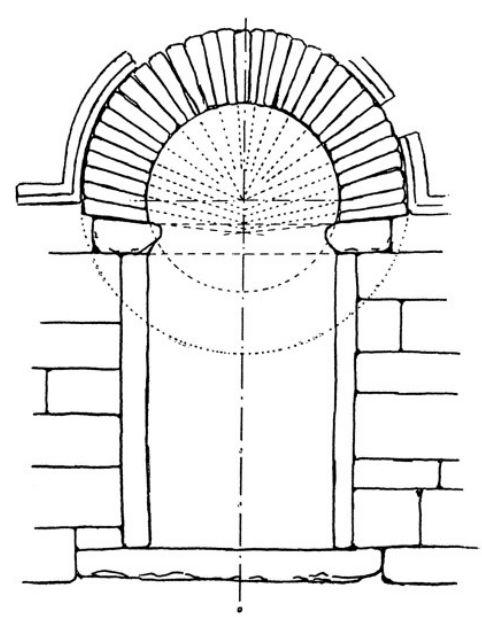

Fig. 1 - Geometría del arco de Santa Eulalia de Bóveda (CAMPS CAZORLA, 1953).

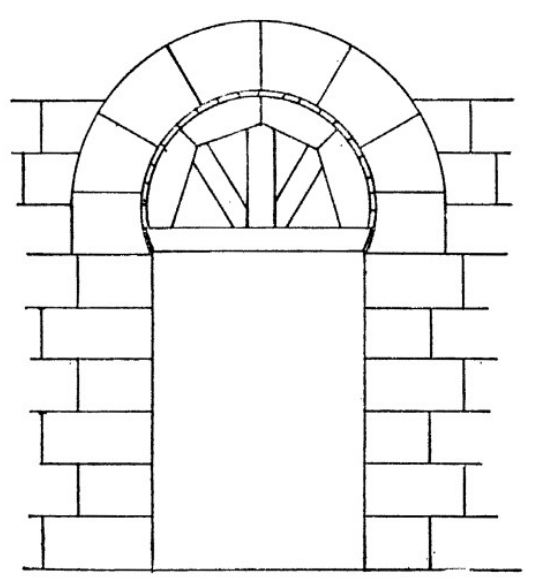

Fig. 2 - Funcionalidad del arco de herradura (CORZO, 1978).

Precisamente, por la excelencia de la arquitectura del templo y la vislumbrada monumentalidad del arco, debería haber sido considerado hace tiempo como un caso paradigmático dentro del arte clásico.

\section{ATRIBUCIÓN ORNAMENTAL/FUNCIONAL DEL ARCO DE HERRADURA}

La mayoría de los investigadores son de la opinión de que la aplicación arquitectónica del arco de herradura estaría justificada exclusivamente por necesidades decorativas. Su argumentación está basada en que el arco de medio punto reúne los requisitos de máxima eficiencia que definen la función arquitectónica básica del arco: descargar hacia sus extremos la fuerza ocasionada por el peso del área constructiva que se encuentra sobre él. Por lo tanto, todo lo que suponga un exceso de $180^{\circ}$ en el ángulo del arco no tendría razón de ser desde un punto de vista estructural.

Siempre me ha llamado positivamente la atención la aportación realizada por Ramón Corzo a esta discusión. Cómo consiguió identificar una aplicación práctica a este "exceso" de segmento de circunferencia al atribuirle la función de imposta. Entre ambos extremos, por lo tanto, el arco permite sustentar la cimbra sobre la que se construye el propio arco sin necesidad de recurrir al apuntalamiento del vano (o de utilizar una imposta propiamente dicha). Esta solución resulta ser un recurso de fábrica muy útil para casos como el de Santa Eulalia de Bóveda, de carácter subterráneo, en los que a pesar de tener un único vano de acceso permite alzar el arco sin interrumpir la entrada con unos incómodos puntales sobre el suelo, evitando así paralizar otras tareas constructivas (Fig. 2). Igualmente, como puntualiza Ramón Cor- 
zo, la aplicación de esta solución resulta eficiente en la construcción de puertas de murallas, al no impedir el tránsito hacia/desde la ciudad, o en puentes y acueductos, al evitar así el apuntalamiento sobre el lecho del río, por ejemplo 4 .

\section{UNA APROXIMACIÓN AL ARCO DE HERRADURA EN ÉPOCA ROMANA}

Su difusión en elOccidente romano está asociada fundamentalmente a influencias del mundo oriental, donde se han de tener en cuenta los precedentes sirios aportados por Ernest Dewald ${ }^{5}$ para justificar el origen del arco de herradura en la Península Ibérica. En este mismo ámbito geográfico, Leopoldo Torres Balbás lo vincula con la llegada de las divinidades orientales al hacer referencia a esta forma arquitectónica en estelas frigias ${ }^{6}$, de las que localiza ejemplares de época romana en el Museo de Esmirna. Este posible origen frigio del arco de herradura ya había sido tenido en cuenta anteriormente por Auguste Choisy precisamente al llamar la atención sobre este tipo de estelas pero prescindió documentarlas gráficamente ${ }^{7}$.

Anteriores investigaciones españolas ya habían manifestado el interés para la historia del arte hispanorromano de la representación de arcos de herradura en estelas funerarias de los siglos II y III ${ }^{8}$ y de las que Manuel Gómez-Moreno ofrecía una primera recopilación de las localizadas en la Península Ibérica en su conocido artículo9 en el que admite el origen oriental del arco de herradura en Persia y Asia Menor con un probable foco primigenio en la India en donde fachadas de templos esculpidos en roca reflejan que el arco de herradura presente en ellas está tomado de modelos de edificios de madera ${ }^{10}$. Sin embargo, los numerosos hallazgos de estelas funerarias de época romana con marcada incidencia del arte indígena (Fig. 3) le permiten proponer un foco secundario en la Península Ibérica de influencias indoeuropeas ${ }^{11}$.

4 Conzo, 1978, p. 127-131. Para el estudio sobre la aplicación funcional del arco de herradura para este tipo de arquitecturas en época hispano-musulmana también resulta de interés la obra de BERMúdEZ, 1995.

5 Dewald, 1922, p. 319-321, 330 y Apéndice I. Vide infra.

6 Torres Balbás, 1965, p. 364 n. 68.

7 Cholsy, 1883, p. 166 n.1.

8 Fita, 1881, p. 390; Redondo, 1904, p. 24-25.

9 Gómez-Moreno, 1906, p. 792.

10 Gómez-Moreno, 1906, p. 787-788, 810-811. Posteriormente, Rivoira (1918: $106,111,112,117,151)$ documentará varios de estos templos gráficamente.

11 Además de la conocida obra de Manuel Gómez-Moreno, pueden resultar de interés para el seguimiento de las diversas teorías sobre el origen del arco de herradura, entre otros, la obra de K. A. C. Creswell sobre arquitectura paleoislámica (CRESwELL, 1979, p. 198-201) y, concretando la situación de la Península Ibérica, el posterior estado de la cuestión elaborado por Luis Caballero Zoreda en su estudio sobre el arco de herradura en Santa María de Melque (CABallero, 1977-78). 

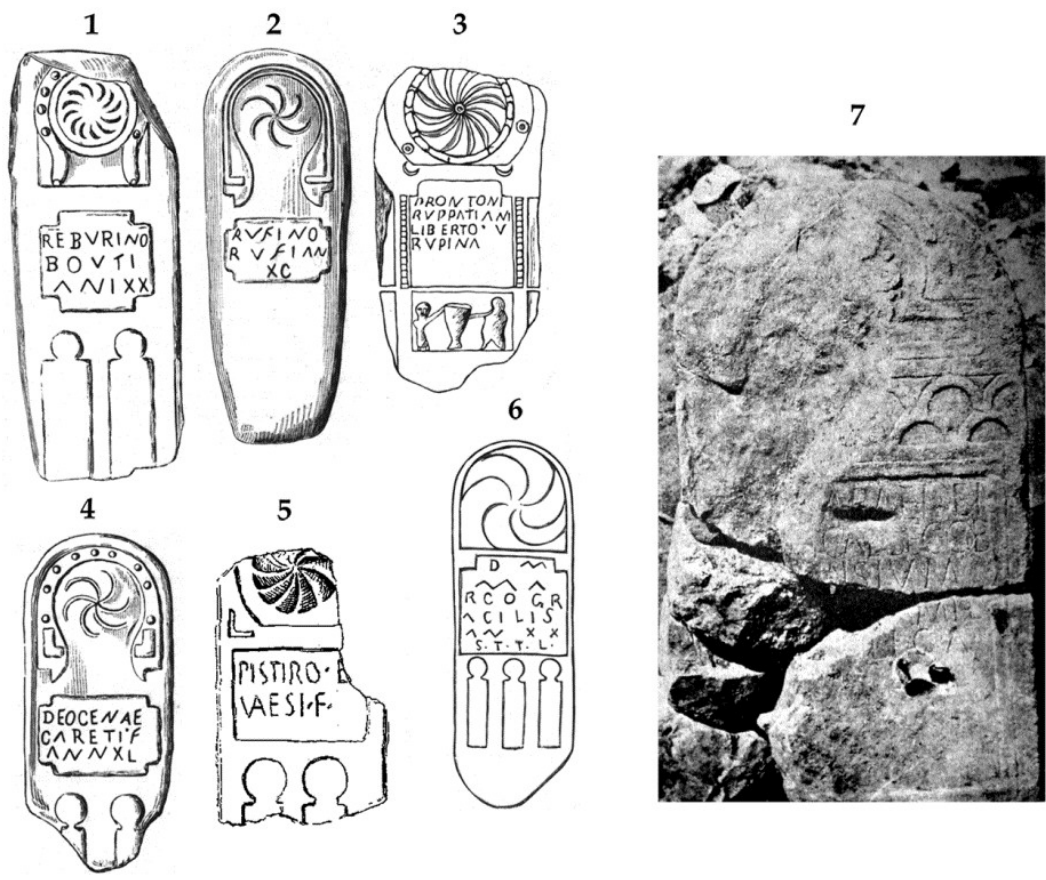

Fig. 3 - Algunas estelas referenciadas por Manuel Gómez-Moreno pero no ilustradas en su artículo sobre el arco de herradura. 1-4: LOPO (1899-900: 144). 5: GómEZ-MORENO (1904: 157). 6: LOPO (1906: 83). 7: FITA (1892: 136).

Manuel Gómez-Moreno desconocía las estelas frigias y lamenta que Auguste Choisy no hubiera incluido imágenes en su obra ${ }^{12}$. Revisando esta circunstancia, he podido comprobar que en la obra previa, y hasta cierto punto preparatoria, de L'art de bâtir chez les byzantis (1883) en la que narra el periplo por Asia Menor, Auguste Choisy describe una estela frigia ${ }^{13}$ que si no se corresponde con una referenciada por Leopoldo Torres Balbás perteneciente al Museo de Esmirna (Fig. 4) sería otra muy semejante (Fig. 5) ${ }^{14}$. Este tipo de estelas con representaciones de puertas asociadas a monumentos funerarios se revelarán de gran interés para este artículo.

Por su parte, Giovanni Rivoira se hace eco del posible foco occidental del arco de herradura, sin embargo incide en la ausencia de arcos arquitectónicos y en la escasa presencia de ejemplares decorativos para acreditarle un uso esporádico. De igual manera opina que ocurriría en el ámbito de la península itálica de época imperial donde señala los

12 Gómez-Moreno, 1906, p. 786.

13 Choisy, 1876, p. 165.

14 AzIZ, 1933, p. 82. 


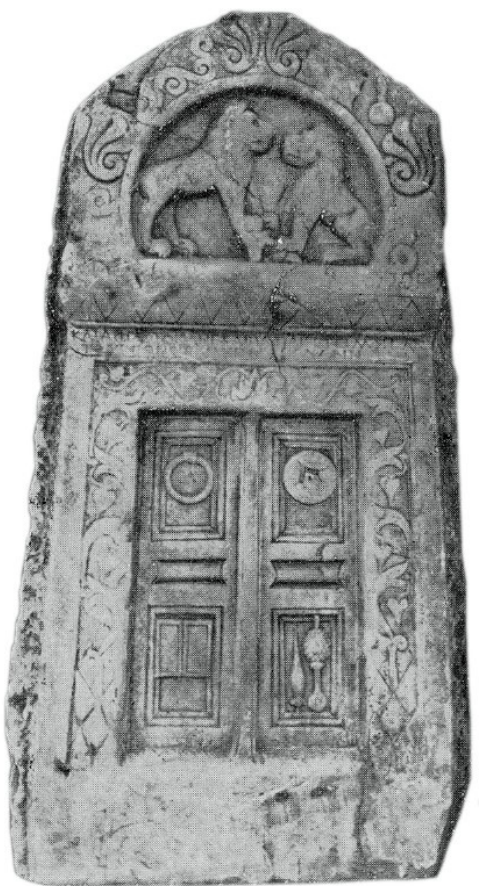

Fig. 4 - Estela frigia, nº 86 (Azız, 1933).

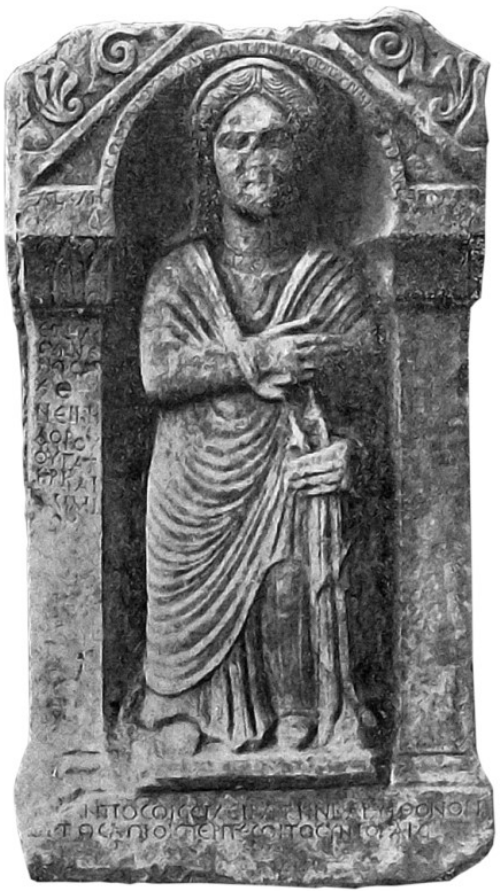

Fig. 5 - Estela frigia, nº 247 (Azız, 1933).

casos excepcionales localizados en las villas próximas a Roma de Sette Bassi y Mattei sul Celio (Fig. 6) situadas cronológicamente en la primera mitad del siglo II y en torno al siglo III-IV, respectivamente ${ }^{15}$.

El posterior artículo de Ernest Dewald tiene el valor añadido de incluir un apéndice con un amplio catálogo de manifestaciones del arco de herradura, y en el que adquiere una relevancia especial, para el asunto a tratar, los arcos localizados en el Occidente romano ${ }^{16}$. Éstos, según el autor, llegarían inicialmente a Italia, Francia y España a través de colonos sirios teniendo en cuenta el referente del monumento funerario de Brâd (Siria), que con una cronología entre la segunda mitad siglo II e inicios del III estaría considerado como el arco de herradura más antiguo de entre los reconocidos de época romana, o al menos en Oriente (Fig. 7). Lamentablemente Ernest Dewald desconocía el artículo de Manuel Gómez-Moreno y sólo contempla ejemplos de León indirectamente a través de otros autore ${ }^{17}$; por el contrario incorpora un buen número de relieves galo-romanos (Fig. 8), presentación de un estilo más

15 Rivolra, 1918, p. 134-136, 241-242.

16 Dewald, 1922, p. 321-322 y Apéndice II (C).

17 Se basa fundamentalmente en la obra de Josep Puig i Cadafalch y Leicester Holland, donde este último toma, asimismo, lo comentado por Manuel Gómez-Moreno 


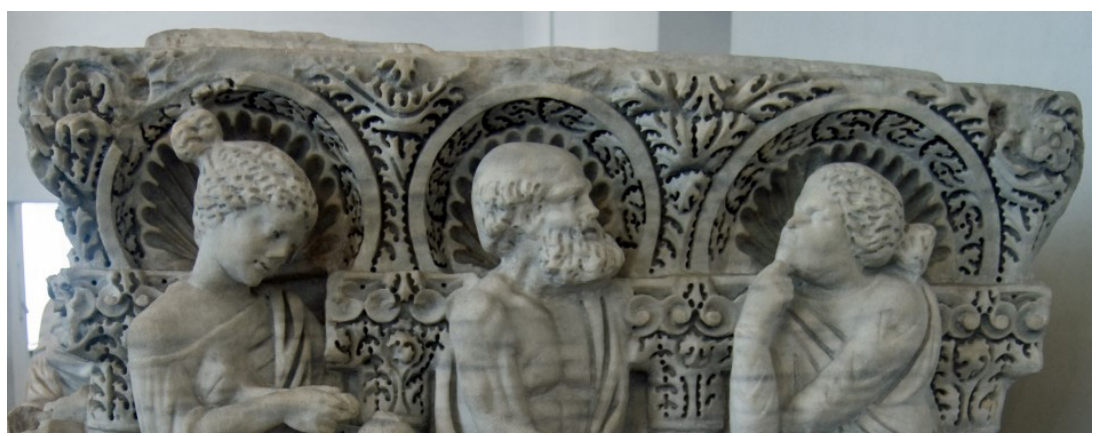

Fig. 6 - Detalle del lateral de un sarcófago de mármol localizado en la villa Mattei sul Celio (Museo Nazionale Romano).

clásico que los del noroeste peninsular (Fig. 3), y varios ejemplos tanto arquitectónicos como decorativos de Italia.

Pero del ámbito itálico sólo resalta los casos más tardíos como es el caso del arco triunfal de San Apollinare in Classe en Rávena y de los relieves de dos sarcófagos de la misma iglesia y el ya mencionado de la villa Mattei sul Celio, entre otros, y que presentan una mayor sintonía con su tesis de la aportación colonial desde Oriente. Sin embargo, desde el punto de vista del ámbito cristiano hispano, convendría tener en consideración la matización de Luis Caballero cuestionando el influjo directo sirio a favor de una intermediación norteafricana ${ }^{18}$.

Curiosamente Ernest Dewald relega otros ejemplos arquitectónicos de su propio catálogo en su argumentación sobre el origen del arco de herradura en Occidente: el del ábside de un edifico del foro de Pompeya y el que se encuentra en el interior del gran vano de acceso al Panteón de Roma, de cronología posiblemente anterior al monumento funerario sirio de Brâd.

Entre otras aportaciones de interés, para la Península Ibérica Helmut Schlunk incorpora el arco de la denominada puerta de Évora en la muralla romana de Beja ${ }^{19}$ y Leopoldo Torres Balbás el relieve arquitectónico localizado en la iglesia de San Marcos en Sevilla ${ }^{20}$ que recuerda mucho a los relieves galos (Fig. 8, 1077).

de Vicente Lampérez y del propio Josep Puig i Cadafalch (Holland, 1918; Lampérez, 1908; Puig i Cadafalch, Falguera, Goday, 1909).

18 Caballero, 1977-78, p. 361-363.

19 SCHLunk, 1935, p. 10.

20 Torres BALBÁs, 1965 , p. 364-365, fig. 168. En la nota 68 insiste en la temprana cronología de uno de los relieves galos, puesto que sus rasgos epigráficos (recogido aquí en Fig. 8, número 31) lo sitúan en el siglo I (Espérandieu, 1907, p. 35-36). Ernest Dewald atribuye erróneamente este cipo al siglo IV. 


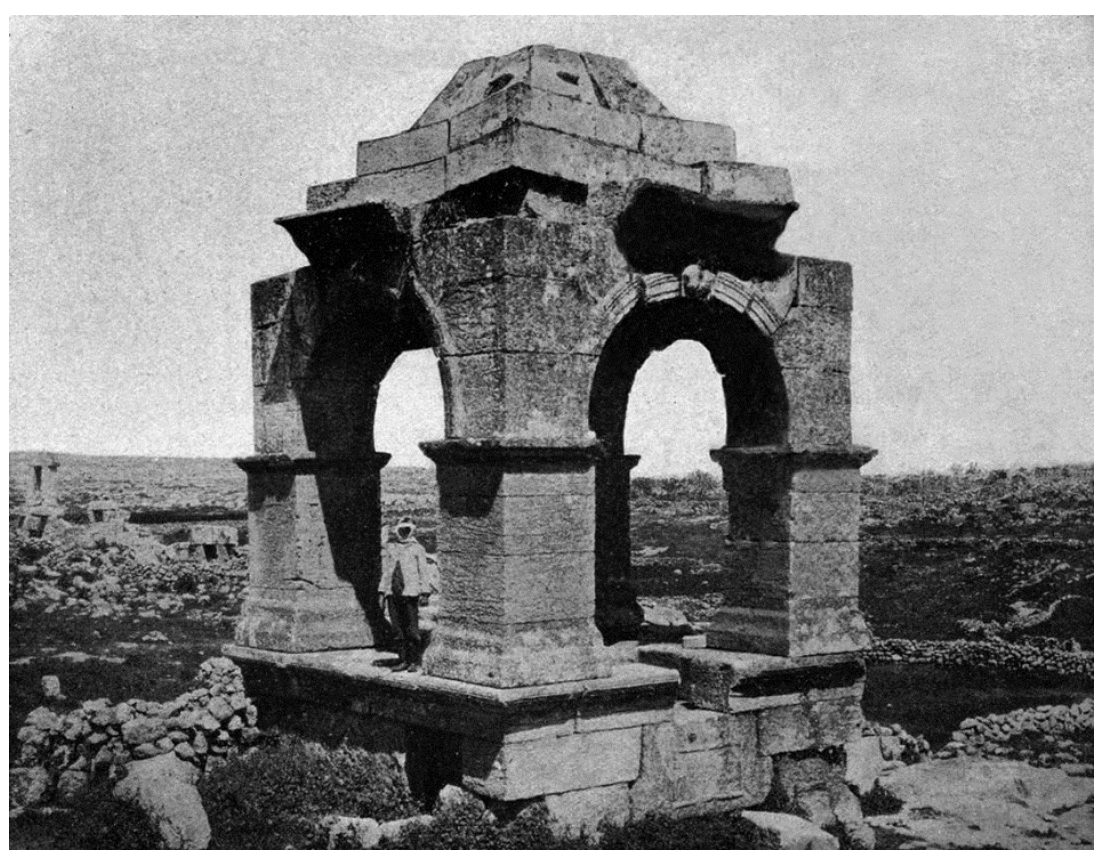

Fig. 7 - Mausoleo de Brâd, Siria (ButLER, 1920).

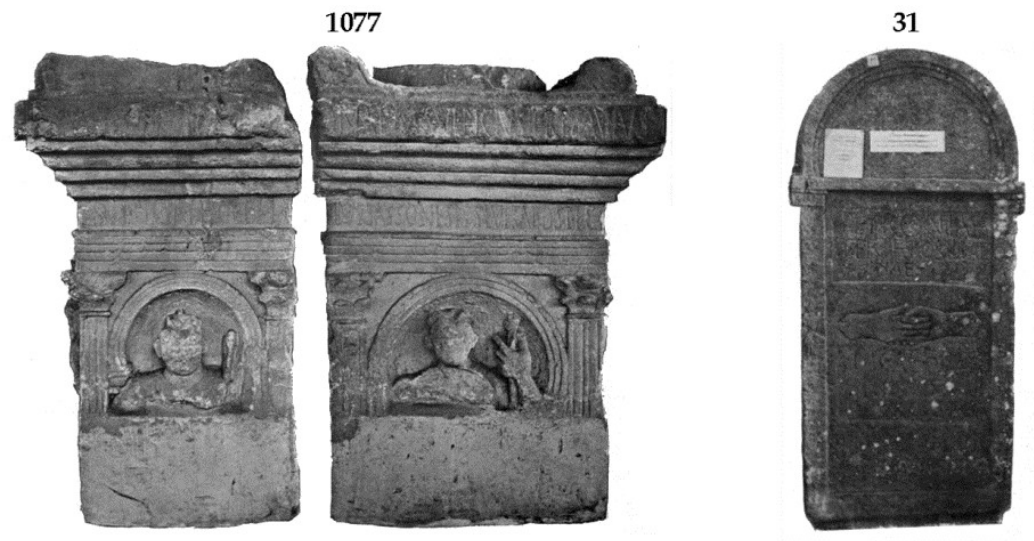

Fig. 8 - Algunas representaciones del arco de herradura en relieves galo-romanos (ESPÉRANDIEU, 1907).

\section{LA ESTELA DE VALENS}

Localizada entre el material constructivo de la muralla romana de León tras producirse un derrumbe en el ángulo oeste del lienzo sur, junto a la plaza Conde Luna, a mediados del siglo XIX. Fue dada a 


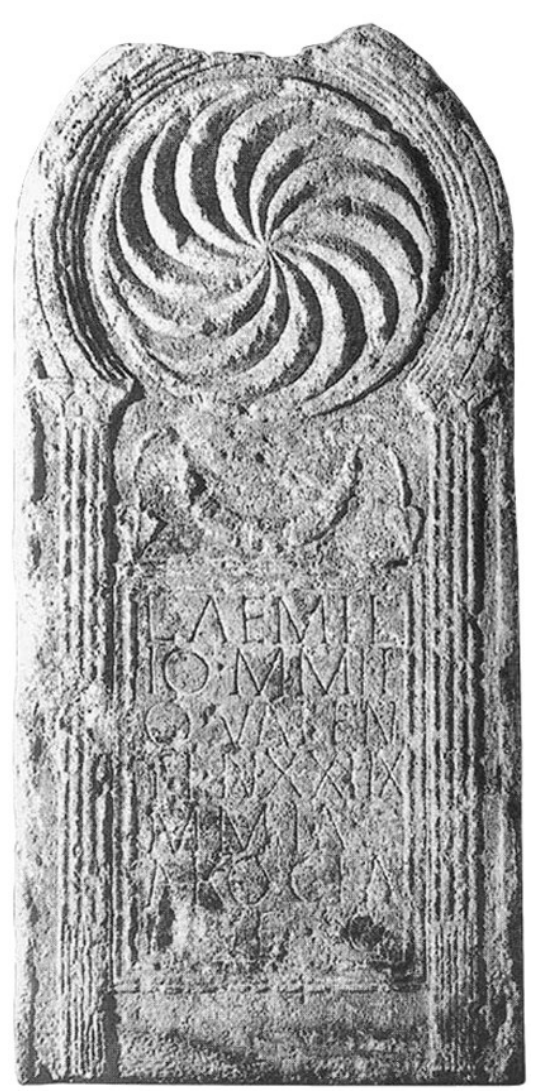

Fig. 9 - Foto de la estela de Valens, Museo Arqueológico Nacional ( $n^{\circ}$ inv. 16502).

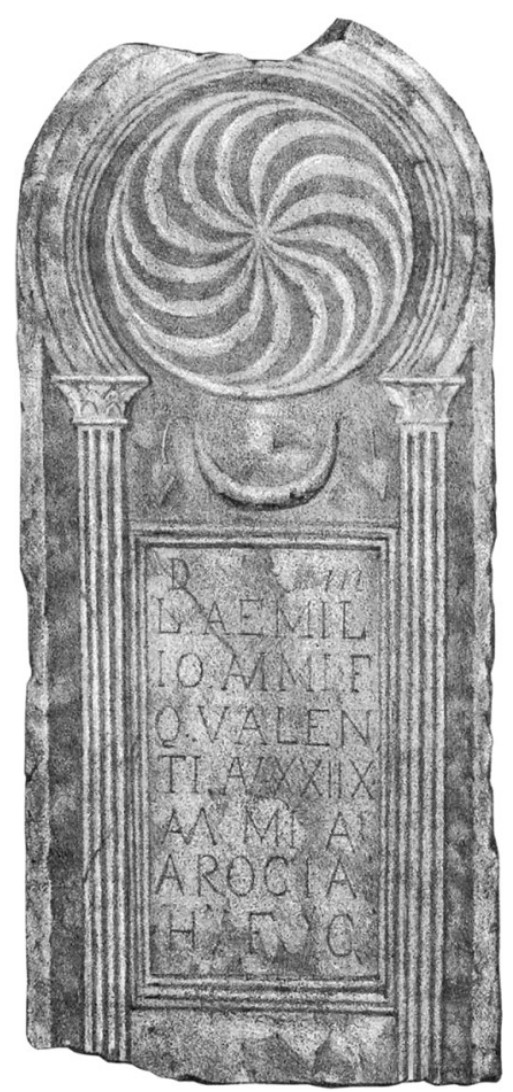

Fig. 10 - Dibujo de la estela de Valens, con anomalías (FITA, 1881).

conocer por Fidel Fita en una serie de publicaciones que compusieron progresivamente su estudio ${ }^{21}$.

Presenta diversas peculiaridades tanto en los motivos decorativos como en el campo epigráfico.

L(ucio) Aemil/io Ammif(ilio) / Q(uirina) Valen/ti an(norum) XXIIX / Ammia / Arocia / h(eres) f(aciendum) c(uravit)

Desde su descubrimiento llamó la atención la filiación a la tribu Quirina del fallecido, destacándose igualmente el origen indígena, a pesar de la tria nomina, por el nombre del padre que coincide con el patronímico de la dedicante, lo que atribuiría a ésta un parentesco cercano, siendo muy probable que fuera su hermana ${ }^{22}$. A pesar de que ella

21 Fita, 1866, p. 165, 167-169 (20); Fita, 1872, p. 466; Fita, 1881, p. 390, 453. Otras ediciones de interés: CIL II, 2675; Diego, 1986, 156; Rabanal, García, 2001, 107.

22 Gallego, 2015, p. 221 n. 23. 
no posee un gentilicio romano costa como heredera presuponiéndole, por lo tanto, su condición de ciudadana latina y donde la legitimidad testamentaria estaría ligada a imitaciones de fórmulas romanas por carecer de la condición jurídica del fallecido ${ }^{23}$.

La promoción social a la ciudadanía romana de Valens podría haber sido determinada por el desempeño de una magistratura vinculable al municipio de Legio o también por su incorporación al ejército como así lo atestiguan otros ejemplos del mismo conventus jurídico con idéntico cognome en el siglo I. La datación epigráfica preferente la situaría a esta estela en el siglo II que no impide una asignación cronológica a la centuria anterior ${ }^{24}$.

Sin embargo, lo más significativo de esta estela está relacionado con su decoración, especialmente con un gran arco de herradura que se distingue entre otros motivos arquitectónicos. Ya desde primera imagen publicada de la estela ${ }^{25}$ llamaría su atención como muestra precursora del uso de este peculiar elemento arquitectónico en la Península Ibérica, evidenciándose, por ejemplo, su significación en el mencionado trabajo de Manuel Gómez-Moreno lo que le otorgaría una mayor transcendencia en la historia de la arquitectura española ${ }^{26}$.

\section{El Panteón de Roma}

Construido por Marco Vipsanio Agripa durante su tercer consulado, en el año 27 a.C., el Panteón es una de las obras arquitectónicas más carismáticas del arte romano. Este gran templo de planta circular proyectado con una majestuosa pronaos fue consagrado a todos los dioses. Constituye uno de los monumentos arquitectónicos romanos mejor conservados, sin embargo la forma constructiva con la que ha llegado a nuestros días es el resultado de la reconstrucción practicada por el emperador Adriano en el siglo II tras su destrucción en un incendio acaecido durante el imperio de Domiciano.

Su arquitectura representa una impresionante muestra de los logros aportados por la ingeniería romana a través de la eficiente aplicación del hormigón para crear amplios espacios interiores. Sobre su base circular se eleva una estructura cilíndrica coronada con una grandiosa cúpula horadada cenitalmente con un amplio óculo. Es espacio resultante es tan amplio y proporcionado que en él se inscribe una esfera cuyo diámetro se corresponde con la anchura y altura del interior.

23 Gallego, 2003, p. 188-189 y n. 49; Gallego, 2014, p. 91 n. 29; Gallego, 2015, p. 221 n. 23.

24 Gallego, 2003; Gallego, 2014, p. 91 n. 29; Redentor, 2002, p. 48; Sastre, 2002, p. 60 n. $42,68$.

25 FitA, 1881, p. 453.

26 Gómez-Moreno, 1906, p. 10-11. 


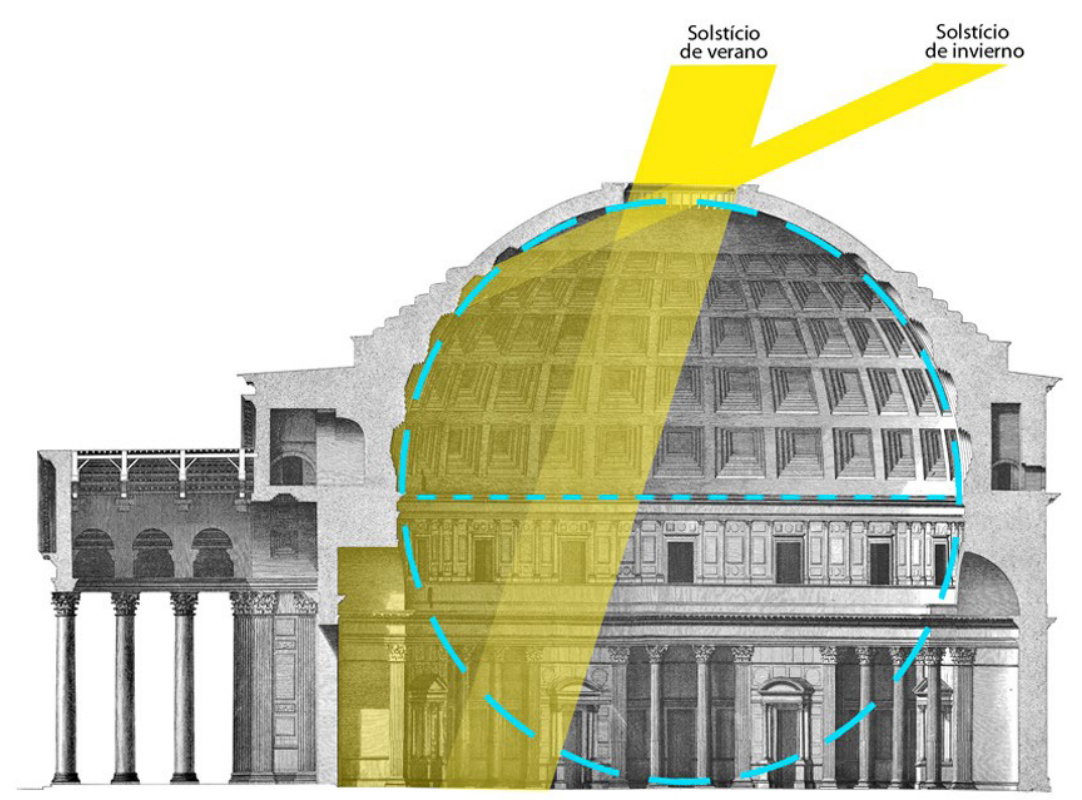

Fig. 11 - Área de incidencia solar a mediodía, sobre un diseño de 1682 de Antoine Desgodetz.

\section{La conmemoración de un fasto imperial}

Un reciente estudio en el que se atribuye un destacado protagonismo al papel del Sol llena de significado determinados aspectos del diseño arquitectónico del Panteón, concretamente los relacionados con la función del óculo localizado en el centro de la cúpula ${ }^{27}$. Se comprueba que, a lo largo del año, el Sol de mediodía atraviesa el óculo incidiendo a nivel de los ejes vertical y horizontal del vano de acceso. En el invierno este haz solar se proyecta sobre la mitad superior de la esfera inscrita en el interior del templo (área de los casetones de la cúpula) y durante el resto del año en su mitad inferior (tramos inferiores del paramento y pavimento) (Fig. 11).

Extrapolando esta característica a todo el horario solar se atribuye al Panteón una función de calendario en el que el haz solar incidiría sobre algunos de los elementos decorativos del interior anunciando determinadas efemérides del ciclo anual. Entre ellas las señaladas por los hitos equinocciales, con especial relevancia simbólica en la primavera debido a que el haz solar del mediodía que entra por el óculo de la cúpula incide sobre el vano de acceso y logra salir al exterior del edificio (Fig. 12, izq.).

Pero en su artículo, Robert Hannah y Giulio Magli destacan especialmente el momento en que el haz de luz incide por primera vez en al 

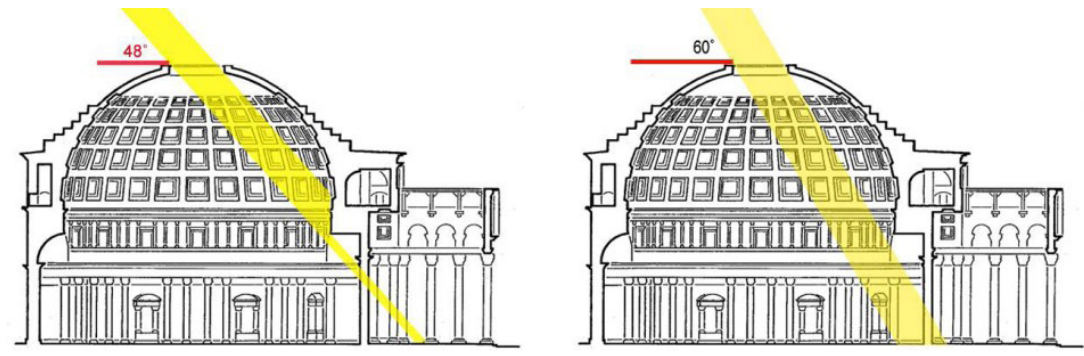

Fig. 12 - El haz solar a mediodía en los equinoccios (izq.) y el 21 de abril (der.). En relación con el ángulo de incidencia solar en los solsticios de verano e invierno señalan $72^{\circ}$ y $24^{\circ}$ respectivamente (HANNAH, MAGLI, 2011).

año sobre el pavimento interno del Panteón al mismo tiempo que ilumina plenamente la entrada. Este instante coincidiría con el mediodía del 21 de abril (Fig. 12, dch.), fecha en la que la tradición designaba la fundación de Roma ${ }^{28}$.

Desde el equinoccio de primavera, cuando trascurridos los largos meses de otoño e invierno los rayos del Sol lograban surgir de nuevo al exterior del Panteón sobre el suelo, a escasos metros de su entrada, hasta el 21 de abril que incidían sobre la base misma de la puerta de acceso, el Sol iba señalando tanto el recorrido como el momento en el que se invitaba al pueblo de Roma a la monumental estancia consagrada a sus dioses. Según indican los autores del artículo este acto estaría personalizado por el propio emperador que accedería al interior del Panteón convocado y acompañado por la deidad solar el día en el que se conmemoraba la fundación de la ciudad eterna.

La excelsa escenografía de este magno evento manifestada en un espacio público comportaría la glorificación del poder del emperador y de la propia Roma además de la gestación de las bases con las que fundamentar el establecimiento del culto imperial.

\section{Un evento significativamente revelador de la arquitectura del Panteón}

No obstante lo anterior, teniendo en cuenta la estructura arquitectónica del Panteón considero que tuvo que existir otro hito ceremonial trascendental desde el punto de vista simbólico en el que, contrariamente a lo indicado en el fasto imperial, el evento se desarrollaría en el interior del edificio.

Es en este momento cuando toma protagonismo el arco de herradura presente en el Panteón, una estructura arquitectónica peculiar que no ha merecido especial atención en la historia del arte romano a pesar de formar parte de uno de los monumentos más carismáticos y representativos de su arquitectura. Aquí, el arco de herradura se conjuga con 


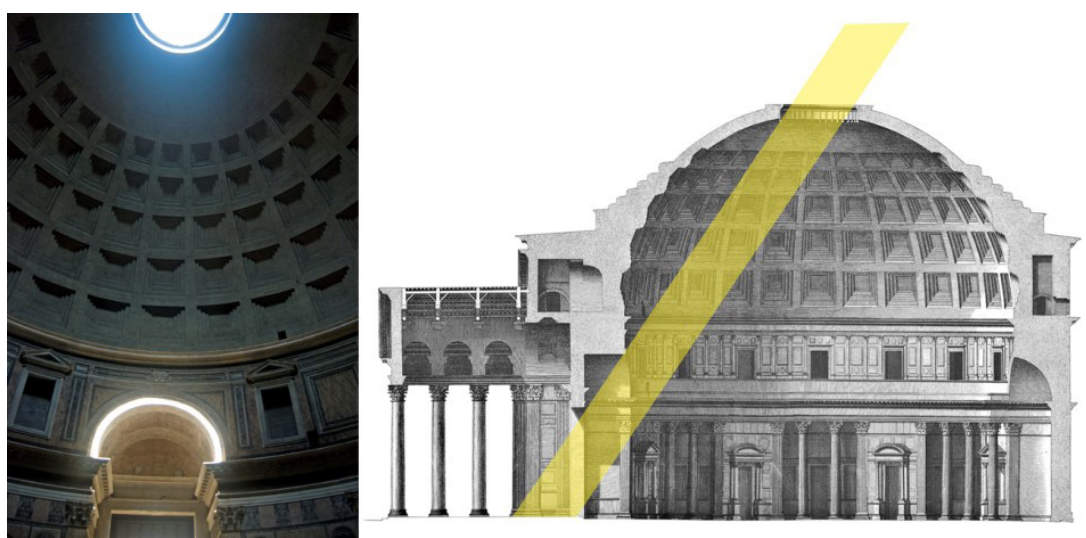

Fig. 13 - El haz solar a mediodía del 3 de septiembre de 2016, 19 días antes del equinoccio.

el Sol de mediodía para erigirse en elementos primordiales con los que fundamentar la fábrica de tan majestuoso templo.

Tras atravesar el óculo cenital, el haz solar incide plenamente en el arco de herradura que corona el interior del portón (Fig. 13). Este acontecimiento se produce dos veces al año, en los primeros días de los meses de abril y septiembre, vinculados temporalmente con los dos equinoccios (19 días después del de primavera y antes del de otoño).

En contraste con el resto de eventos del calendario solar ahí representado, la preeminencia del instante en el que ambas aberturas estarían ensambladas mediante un conducto solar estaría evidenciada ante la existencia de una ruptura de la armonía constructiva del Panteón protagonizada, precisamente, por la presencia del arco de herradura. Es decir, el sentido primordial del diseño original del Panteón (o al menos el definido en la reconstrucción de Adriano) podría pivotar en torno a este peculiar elemento arquitectónico.

¿Por qué la perfección espacial definida por las proporciones geométricas y la simétrica armonía del interior de un excelso templo se llega a quebrantar fácilmente? La relevancia del uso del arco de herradura en la respuesta se hace patente tanto en el dibujo de Antoine Desgodets como en el realizado por Francesco Piranesi (finales de los siglos XVII y XVIII respectivamente) ${ }^{29}$ en los que se contrastan las mitades de la sección transversal de la entrada y su opuesta (Fig. 14). Es lógico prever que esta simetría ha de romperse en el diseño de un edificio con una única entrada (solucionado en parte con la presencia en el lado opuesto de un área absidal proporcional) pero sorprende el hecho de haber optado por un arco de herradura frente al arco de medio punto como suele ser habitual en las construcciones romanas. En vez de estar

29 Desgodets, 1682, lám. VII; Piranesi, 1790, lám. XI. 

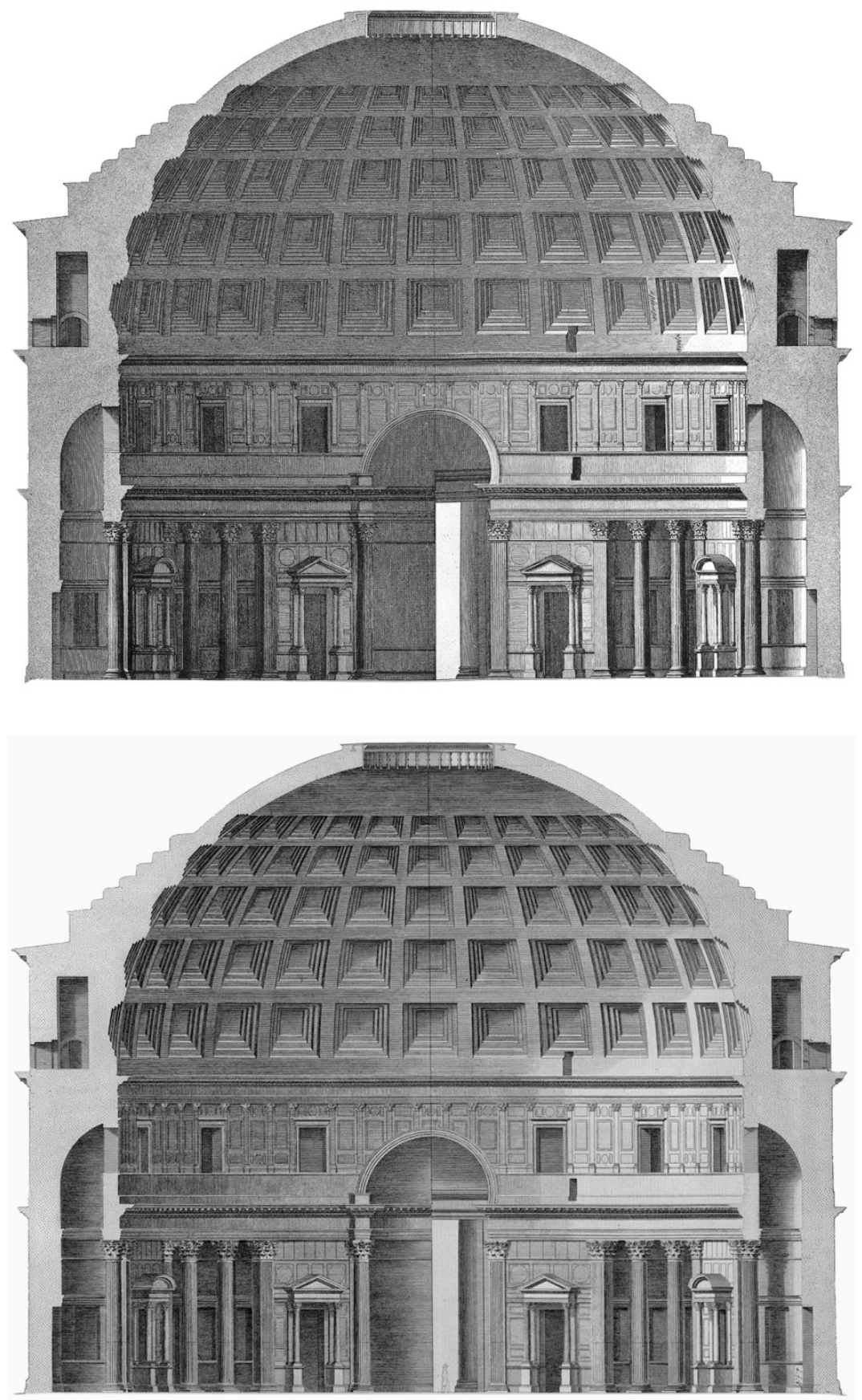

Fig. 14 - Secciones opuestas del interior: Antoine Desgodetz (1682) y Francesco Piranesi (1790). 
apoyado sobre dos pedestales como el opuesto de medio punto, el arco de la entrada se prolonga hasta la cornisa; es de suponer que se optó por esta solución necesariamente para lograr el efecto deseado al conjuntar el arco sobre el vano de acceso con el óculo cenital.

\section{Algunos vínculos del discurso simbólico del Panteón con el mundo fu- nerario}

Retomando el estudio sobre el significado del arco de herradura en el ámbito sepulcral, una vez tenidos en cuenta los resultados aportados en la solución constructiva del Panteón, llama poderosamente la atención lo representado en la estela de Valens en la que un disco solar se encaja igualmente en el interior de un arco de herradura apoyado, en este caso, sobre dos columnas aludiendo esquemáticamente una obra arquitectónica (Fig. 9-10). Es obvio, por lo tanto, que el vínculo simbólico entre estas dos soluciones no se debe ignorar.

Igualmente resulta bastante efectiva la ejemplaridad de la estela leonesa, actualmente depositada en el Museo Arqueológico Nacional, con la que evidenciar la dificultad de adjudicar exclusivamente una funcionalidad meramente decorativa a las representaciones del arco de herradura en estelas funerarias del norte de la Península Ibérica en época romana ${ }^{30}$.

Atribuir un significado exclusivamente funerario al arco de herradura del Panteón se antoja harto complicado pero no se ha de descartar que el simbolismo inherente al culto o al concepto religioso representado en él sea susceptible de ser compartido con el mundo de ultratumba. Hay que tener en cuenta, además, que los dioses ctónicos se dispondrían en la zona sur del interior del Panteón sobre la cual nunca inciden los rayos del Sol ${ }^{31}$. Pero quizá el vínculo por excelencia sea el que identifica el espacio constructivo del Panteón con el lugar donde se produjo la apoteosis de Rómulo ${ }^{32}$.

También hay que tener en cuenta el vínculo existente entre el Panteón y el mausoleo de Augusto que, además de poseer una concepción y dimensiones similares, se alinean enfrentados a media milla de distancia formando parte, junto con el Ara Pacis y el Horologium Augusti, del proyecto monumental de Augusto en el Campo de Marte ${ }^{33}$. Terreno del

30 Uno de los autores más incisivos en este tema ha sido Eugeniusz Frankowski que, precisamente incidiendo sobre esta estela entre otras, descarta cualquier relación de los arcos de herradura en ellas representados con motivos arquitectónicos, decantándose por calificarlos como simples formas decorativas (FrANKOWSKI, 1920, p. 152-154).

31 Hannah, Magli, 2011, p. 497, 503.

32 La Rocca, 2014, p. 131, 151; La Rocca, 2015, p. 67-71, 75-76.

33 Voegtle, 2008, p. 71-76 y fig. 5; Haselberger, 2014; La Rocca, 2014, p. 125 132; LA RoccA, 2015, p. 76-78. Hay que incidir en que el trabajo de Eugenio La Rocca de 2014 es más reciente porque el del año 2015 se entregó a los editores en 2008 sin poder efectuar una revisión previa a su publicación (LA RocCA, 2015, p. 49). 

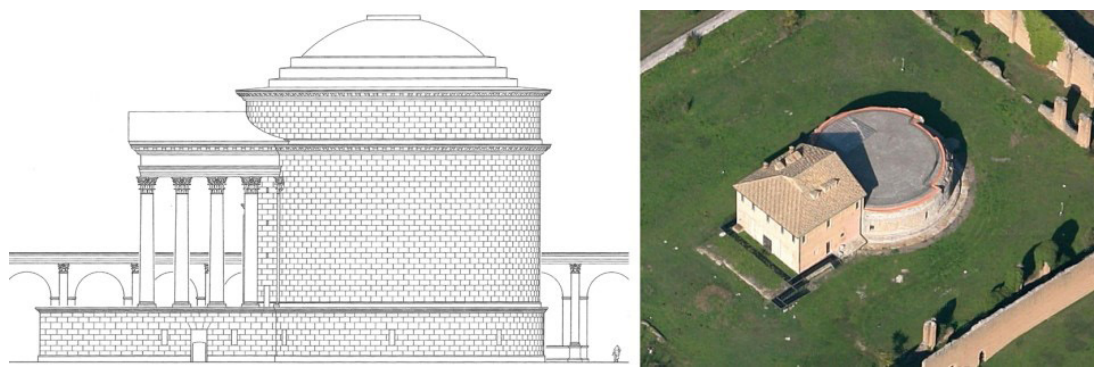

Fig. 15 - Reconstrucción hipotética del mausoleo de Majencio (RASCH, 1984) frente al estado actual del monumento (Google Maps, junio 2013).

que, por cierto, al menos una parte estaría consagrada al ámbito funerario, más allá del área de influencia del mausoleo de Augusto $^{34}$.

La relación entre el mausoleo, diseñado para albergar los restos del primer emperador y de su familia, y el Panteón sugiere que el complejo monumental diseñado por Augusto y sus arquitectos fue concebido como un espacio destinado a promover la sacralidad dinástica del nuevo orden imperante.

Por su parte, el emperador Adriano reconstruyó el Panteón al final del primer cuarto del siglo II y también quiso vincular simbólicamente su mausoleo con el Campo de Marte, reivindicando asimismo la relación de su dinastía con la de Augusto. Construyó su monumento funerario en el punto de intersección definido por la línea equinoccial que pasa por el Ara Pacis y la línea solsticial. Esta última conjunción determina que desde la fachada del Panteón se observaba poner el Sol detrás del mausoleo de Adriano en el día más largo del año ${ }^{35}$.

La relación monumento funerario y Panteón tendría una de sus máximas expresiones dos siglos más tarde con la construcción del mausoleo de Majencio, situado en la mansión que el emperador poseía en la Via Appia (Fig. 15). Pero el estado actual de conservación no permite ser concluyente sobre las evocaciones funerarias potencialmente expresadas con la presencia del arco de herradura del Panteón y que pudieran manifestarse más claramente en este monumento funerario imperial de inicios del siglo $\mathrm{IV}^{36}$.

Una cuestión de interés no tenida en cuenta en el trabajo de Robert Hannah y Giulio Magli que reforzaría el papel del Panteón en el ritual funerario asociado al mausoleo de Adriano tiene que ver con la conjunción de los dos monumentos. El hecho de estar unidos por el trazado de la línea solsticial implica que, además de observarse desde el Panteón el ocaso solar tras el mausoleo de Adriano en el solsticio de verano,

34 La Rocca, 2014, p. 140.

35 Hannah, Magli, 2011, p. 508-510, fig. 13.

36 Haselberger, 2009, p. 183-184. 

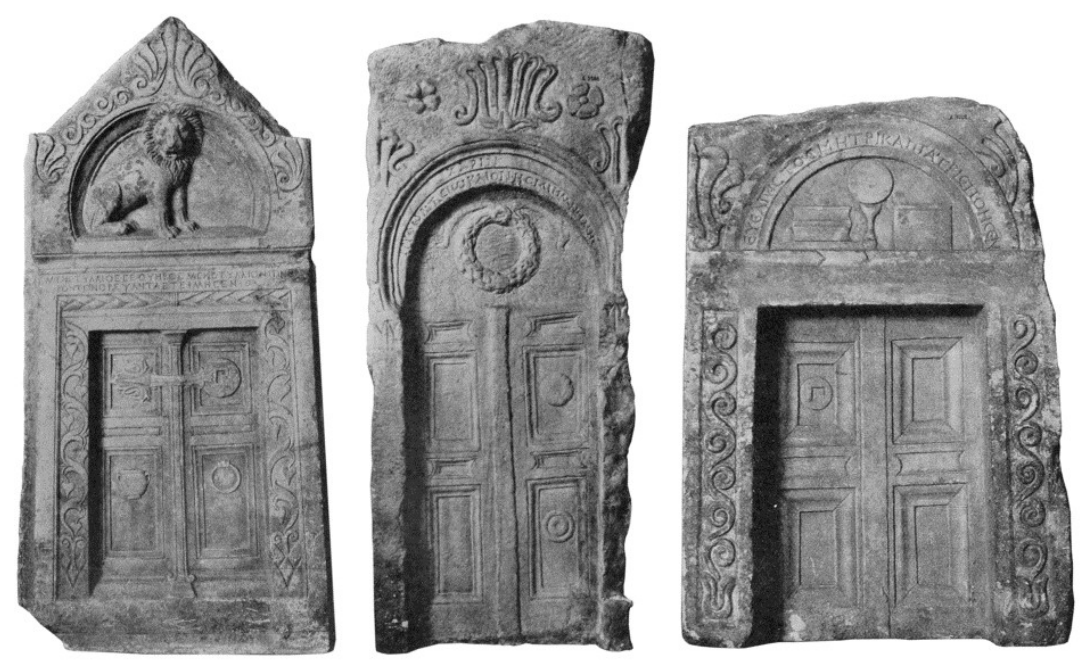

Fig. 16 - Estelas frigias decoradas con representación de puertas de acceso a tumbas, Musée du Cinquantenaire, Bruxelles (CUMONT, 1913), las dos primeras coronadas con arco de herradura.

si invertimos el punto de referencia y nos situamos en el mausoleo en el solsticio de invierno el orto solar se manifiesta tras el Panteón. Esta orientación ha sido una solución aplicada en numerosas tumbas desde tiempos inmemoriales. La fuerza simbólica de enfrentar el sepulcro al punto en el que el Sol retoma su ciclo anual, vinculándolo así con el eterno renacimiento del astro, es evidente que llena de significado vital al mundo de ultratumba de sus moradores.

El hecho de que la fachada del mausoleo de Adriano no esté orientada al orto del solsticio de invierno no debe de ser un impedimento para descartar el vínculo simbólico mausoleo-Panteón-Orto debido al diseño circular del monumento funerario que posibilita una máxima flexibilidad en estos casos. La fachada del evento tiene más libertad para disponerse en el lugar más adecuado teniendo en cuenta el urbanismo o la función propagandística que se le quiera otorgar. El haz solar podría incidir a través de un óculo o cualquier otro vano que permita el acceso al interior o, simplemente, reflejarse sobre cualquier elemento decorativo o arquitectónico dispuesto en el segmento adecuado del paramento exterior del edificio lo que, por otro lado, también facilitaría una efemérides pública del evento.

En las estelas con arco de herradura, o con otra decoración atribuible a una fachada de un monumento funerario, es evidente que tienen mayor flexibilidad que una construcción a la hora de disponerse con la orientación precisa, sólo tienen la limitación de hincarlas en un lugar con la visibilidad adecuada. Pero este requisito también se 

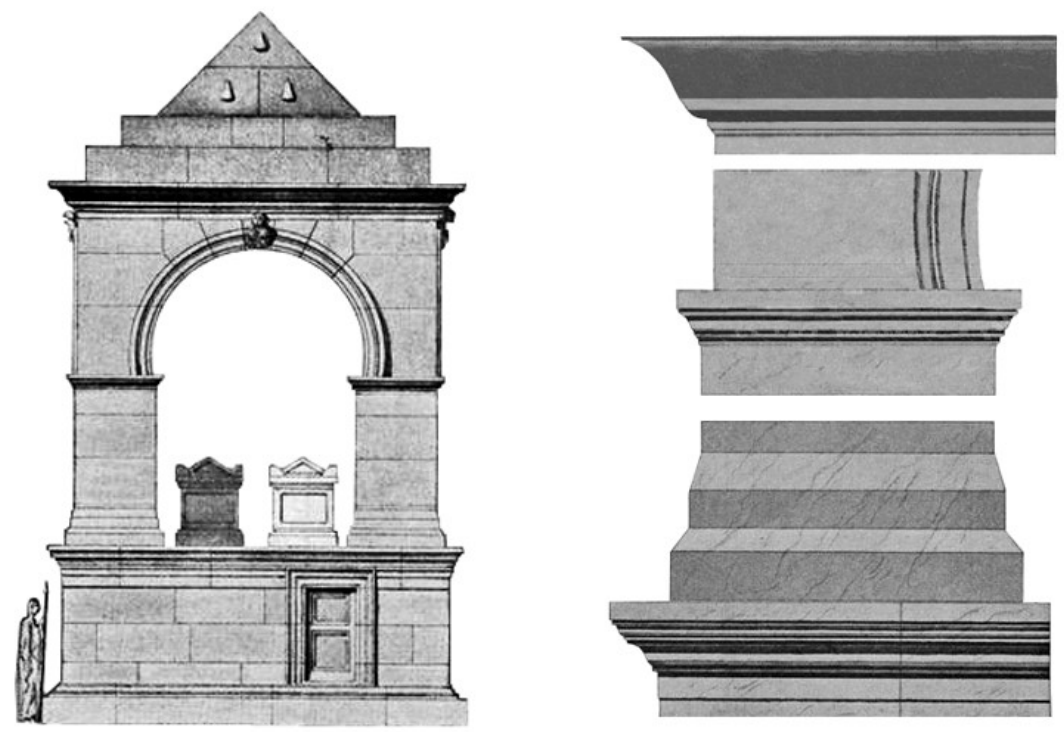

Fig. 17 - Mausoleo de Brâd, Siria, con detalle del arranque del arco (Butler, 1920).

lograría obviar si en la misma estela está representado, con mayor o menor pericia, el evento astronómico deseado; tal puede ser el caso de la espléndida estela leonesa dedicada a Valens.

La calidad artística de las estelas frigias ya indicadas del Museo de Esmirna (Fig. 4) u otras del mismo grupo como por ejemplo las depositadas en el Musée du Cinquantenaire en Bruxelles (Fig. 16) en la que se representan con todo detalle puertas bajo arcos permite identificarlas como representaciones de fachadas de monumentos funerarios escavados en roca muy frecuentes en esa área geográfica ${ }^{37}$. Como en el caso del grupo de estelas del norte peninsular se muestran con arcos de herradura o de medio punto y es muy probable que ambas manifestaciones artístico-culturales estén comunicando la misma idea evidenciada en la fachada del monumento de Bóveda cuya entrada coronada de un arco de herradura está orientada, como preferencia cultual en este caso, al orto equinoccial.

Teniendo en cuenta lo comentado hasta ahora, no debería extrañar que se llegue a identificar en el Occidente romano ejemplares arquitectónicos de arcos de herradura anteriores al siglo II. Pero esto no implica que no exista una relación con Oriente, de marcada influencia helenística, como así lo demuestra la semejanza entre el arco del Panteón con el de Brâd en Siria, al arrancar igualmente de un mismo tipo de cornisa (Fig. 17). 
Pero tampoco hay que descartar un foco secundario en la Península Ibérica como propuso Manuel Gómez-Moreno y también contemplan tanto Jacques Fontaine como Luis Caballero ${ }^{38}$, estos últimos contando con el excepcional arco de herradura de Santa Eulalia de Bóveda.

\section{AgRAdECIMIENTOS}

He de agradecer a Paco Vila Barros su desinteresada colaboración en el tratamiento digital de las imágenes para este artículo.

38 Gómez-Moreno, 1906; Fontaine, 1973; Caballero, 1977-78. 


\section{Bibliografía}

AzIz, A. Guide du Musée de Smyrne, Istanbul, 1933.

BERMúDEZ, J.M. "La forma constructiva de herradura: su función en las obras de infraestructura hispano-musulmana (puentes y acueductos)", Anales de Arqueología Cordobesa 1995/6, p. 239-264.

Butler, H.C. Ancient architecture in Syria. Section B: Northern Syria, Princeton University archaeological expeditions to Syria in 1904-5 and 1909, Leiden, 1920.

Caballero, L. "La 'forma de herradura' hasta el siglo VIII, y los arcos de herradura de la iglesia visigoda de Santa María de Melque", Archivo Español de Arqueología 1977-78/135-138, p. 323-374.

Camps Cazorla, E. Módulo, proporciones y composición en la arquitectura califal cordobesa, Madrid, 1953.

Castillo, Á. "Los descubrimientos de Santa Eulalia de Bóveda", Boletín de la Real Academia Gallega 1927/197, p. 140-142.

Choisy, A. L'Asie mineure et les Turcs en 1875. Souvenirs de voyage, Paris, 1876

Chorsy, A. Lart de batir chez les Byzantins, Paris, 1883.

Corzo, R. “Génesis y función del arco de herradura”, Al-Andalus 1978/43, p. 125-142.

Creswell, K.A.C. Early Muslim Architecture. Volume I, Part I: Umayyads A.D. 622-750, New York, 1979.

Cumont, F.V.M. Catalogue des sculptures et inscriptions antiques (monuments lapidaires) des Musèes Royaux du Cinquantenaire, Bruxelles, 1913.

Desgodets, A.B. Les édifices antiques de Rome. Misurés et dessinés tres-exactement sur les lieux par feu M. Desgodetz architecte, Paris, 1682.

DEWALD, E.T. "The appearance of the horseshoe arch in Western Europe", American Journal of Archaeology 1922/26.3, p. 316-337.

Rabanal, M.A., García, S.M. Epigrafía romana de la provincia de León: revisión y actualización, León, 2001.

EspérANDIEU, É. Recueil général des bas-reliefs de la Gaule romaine. Tome premier: Alpes Maritimes, Alpes Cottiennes, Corse, Narbonnaise, Paris, 1907.

Fita, F. Epigrafía romana de la ciudad de León, León, 1866.

Fita, F. "Legio VII Gemina”, Museo Español de Antigüedades 1872/1, p. 449-469

FitA, F. "Nuevas lápidas romanas de la ciudad de León”, Museo Español de Antigüedades $1881 / 11$, p. 387-394.

FITA, F. "Antigüedades romanas", Boletín de la Real Academia de la Historia 1892/26, p. 129-150.

Fontaine, J. L'art préroman hispanique. V. 1, [Art paléochrétien. Art wisigothique. Art asturien], La Pierre-qui-Virelb. 1973.

Frankowski, E. Estelas discoideas de la Península Ibérica, Madrid, 1920.

GALlEGo, M.H. "Herederas hispanorromanas: su caracterización onomástica y social a través de las fuentes epigráficas”, Hispania Antiqua 2003/27, p. 171-200.

Gallego, M.H. "Disimetrías familiares en el uso del nomen romano en la epigrafía del valle del Duero : Sus implicaciones jurídicas", Espacio Tiempo y Forma. Serie II, Historia Antigua 2014/27, p. 77-94.

Gallego, M.H. “Transmisión onomástica y homonimia en los grupos fami- 
liares del valle del Duero en época romana”, Hispania Antiqua 2015/39, p. 211-242.

Gómez-Moreno M. “Sobre arqueología primitiva en la región del Duero", Boletín de la Real Academia de la Historia 1904/45, p. 147-160.

Gómez-Moreno M. "Excursión a través del arco de herradura", Cultura Española 1906/3, p. 785-811.

Gómez-Moreno M. Misceláneas. Historia - Arte - Arqueología. Primera Serie. La Antigüedad, Madrid, 1949.

Hannah, R. Time in antiquity, London - New York, 2009.

Hannah, R., Magli, G. "The role of the Sun in the Pantheon's design and meaning”, Numen 2011/58, p. 486-513.

Haselberger, L. "The Pantheon: nagging questions to no end", in G. Grasshoff, M. Heinzelmann, M. Wäfler (eds.), The Pantheon in Rome : 1. Contributions to the Conference Bern, November 9-12, 2006, Bern Studies in the History and Philosophy of Science, 1, Bern, 2009, p. 171186.

Haselberger, L. The horologium of Augustus: debate and context, JRA Supplementary series 99, Portsmouth, Rhode Island, 2014.

Holland, L.B. “The origin of the horseshoe arch in Northern Spain”, American Journal of Archaeology 1918/22.4, p. 378-398.

Diego, F. Inscripciones romanas de la provincia de León, León, 1986.

LA RoccA, E. " "Augustus' solar meridian and the Augustan urban program in the northern Campus Martius: an attempt at a holistic view", in L. HASELBERGER, The horologium of Augustus: debate and context, JRA Supplementary series, 99, Journal of Roman Archaeology, Portsmouth, Rhode Island, 2014, p. 121-165.

La Rocca, E. “Agrippas's Pantheon and its origin”, in T.A. Marder, M.Wilson Jones (eds.), The Pantheon. From antiquity to the present, New York, 2015, p. 49-78.

LAMPÉREZ, V. Historia de la arquitectura cristiana española en la Edad Media según el estudio de los elementos y los monumentos, Madrid, 1908.

López-MARTí, L. Santa Eulalia de Bóveda. Descripción y gráficos del monumento allí existente, Lugo, 1934.

Lopo, A. "Picote (Miranda-do-Douro)", O Archeologo Português 1899-900/5.5, p. 143-145.

Lopo, A. "Vestígios romanos em Bragança”, O Archeologo Português 1906/11.14, p. 83-84.

Montenegro RúA, E.J. Santa Eulalia de Bóveda. Estudio histórico-arqueológico y propuesta interpretativa del monumento y su entorno, Tesis doctoral inédita UAM, 2016.

Piranesi, F. Seconda parte de'tempj antichi che contiene il celebre Panteon, Roma, 1790.

Puig i CAdAfalch, J., Falguera, A., Goday, J. Larquitectura romànica a Catalunya, I. Precedents: l'arquitectura romana, l'arquitectura cristiana prerrománica, Barcelona, 1909.

Rasch, J.J. Das Maxentius-Mausoleum an der Via Appia in Rom, Spätantike Zentralbauten in Rom und Latium 1, Mainz am Rhein, 1984.

Redentor, A. Epigrafia romana na região de Bragança, Lisboa, 2002. 
Redondo, I. Iglesias primitivas de Asturias, Oviedo, 1904.

Rivorra, G.T. Moslem architecture. Its origins and development, London, 1918.

SASTRE, I. Onomástica y relaciones políticas en la epigrafía del Conventus Asturum durante el Alto Imperio, Anejo de Archivo Español de Arqueología 25, Madrid, 2002.

Schlunk, H. "Santa Eulalia de Bóveda", in Adolph Goldschmidt zu seinem siebenzigsten Geburtstag : am 15. Januar 1933; dargebracht von allen seinen Schülern, die in den Jahren 1922 bis 1933 bei ihm gehört und promoviert haben: [Umschlagt.:] Das siebente Jahrzehnt, Berlin, 1935, p. 1-13.

ToRres BALBÁs, L. "La arquitectura durante los primeros gobernadores y los emires (710-929)", in E. LÉvi-Provençal, L. Torres Balbás España musulmana hasta la caída del Califato de Córdoba (711-1031 de J.C.), Historia de España 5, Madrid, 1965 p. 337-420.

Voegtre, S. "ubi sepe sedebat Octavianus : Das Augustusmausoleum - Innen und Aussen eines imperialen Grabbaus", in J. Albers, G. Grasshoff, M. Heinzelmann, M. WÄFler (eds.), Das Marsfeld in Rom : Beiträge der Berner Tagung vom 23./24. November 2007, Pantheon, 4, Bern, 2008, p. 63-78. 
